\title{
Whole body MRI more efficient than multiple scans at assessing spread of cancer
}
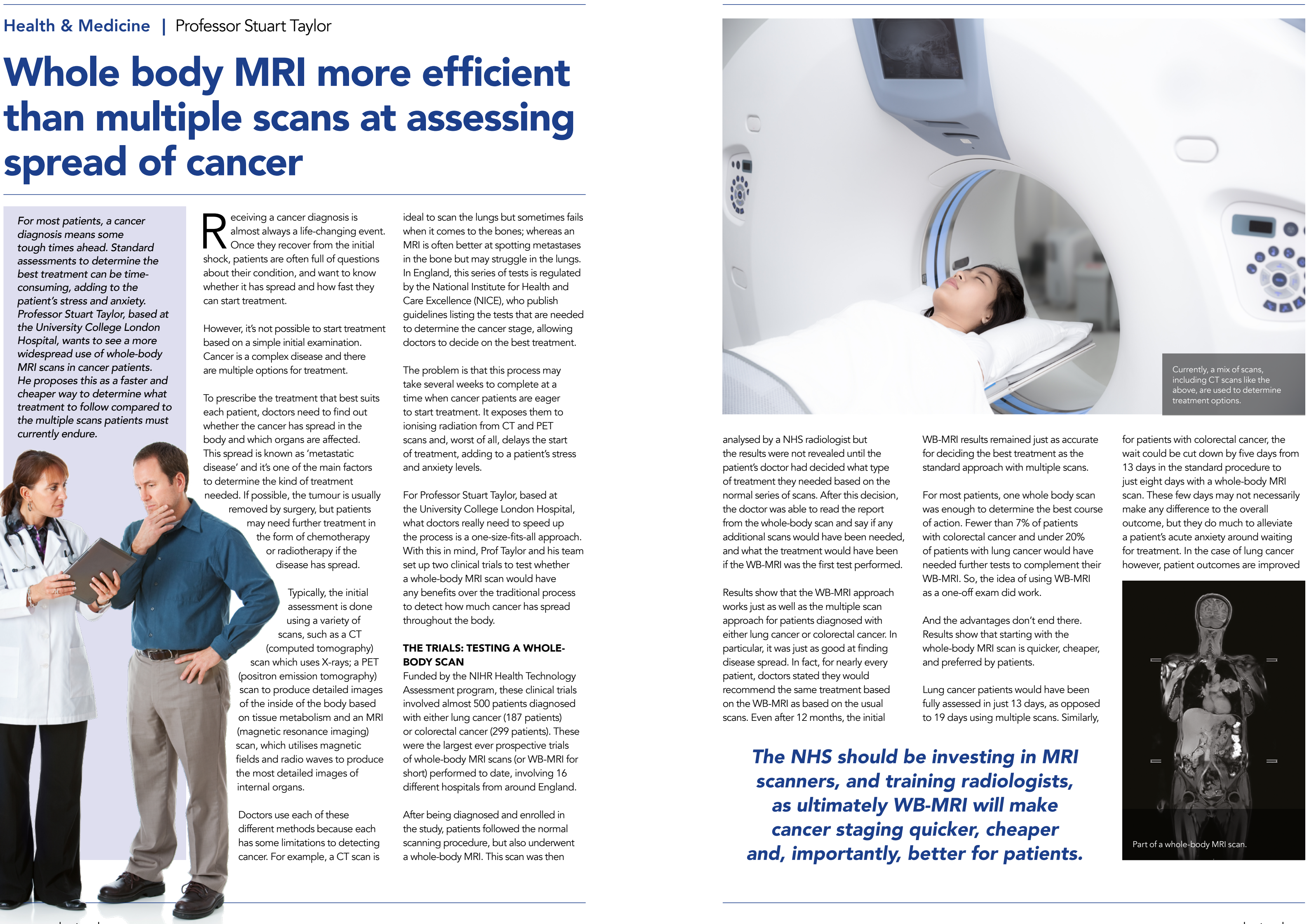


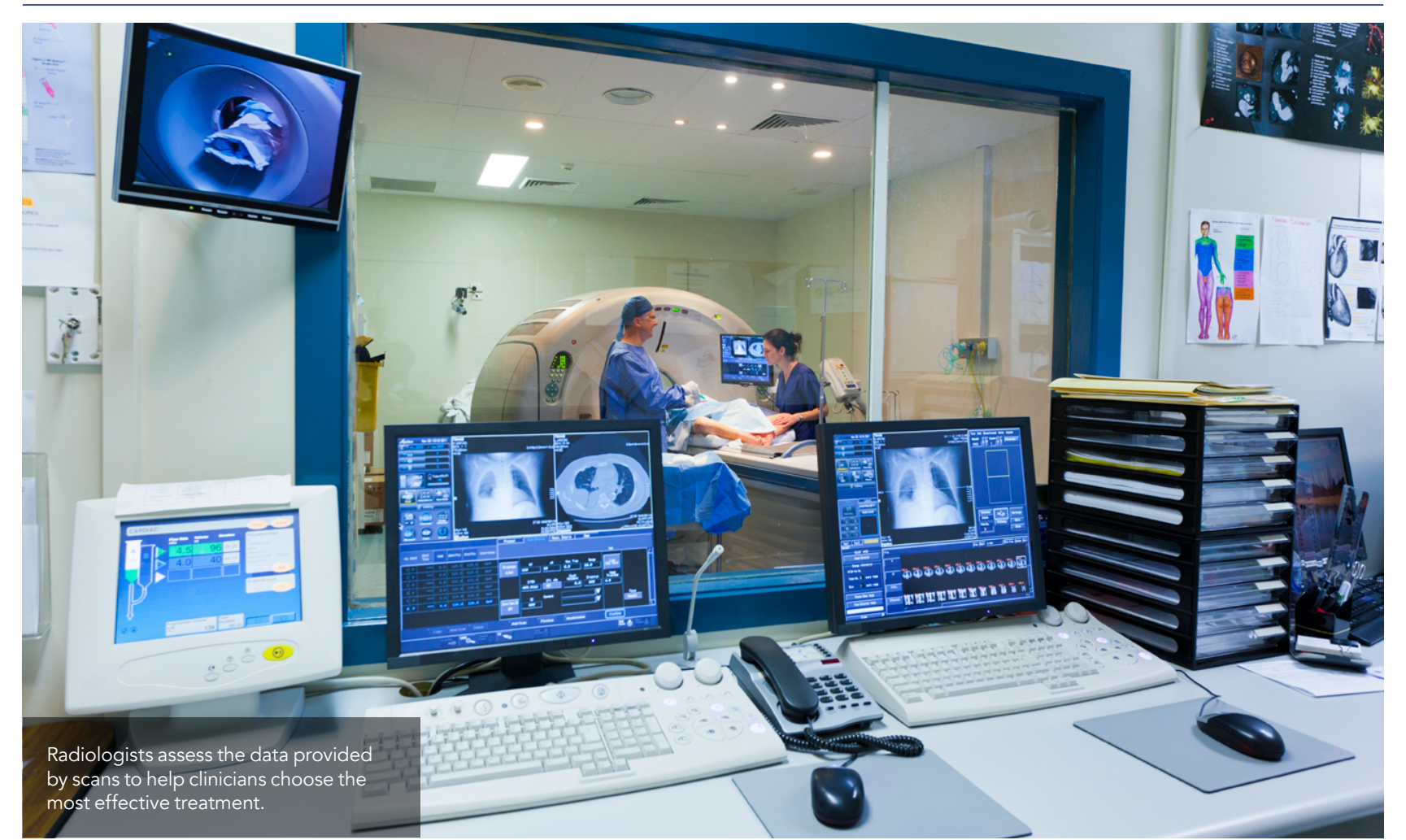

by reducing the time between diagnosis and treatment, even by a short period.

Also, at a time when the NHS is already financially overstretched, news of lower costs associated with the whole-body MRI scan will also be very welcome to
stakeholders. Opting for the single scan stakeholders. Opting for the single scan
can save the National Health Sevice 303 can save the National Health Service f30 per patient in the case of lung cancer and $\mathrm{f} 69$ in the case of colon cancer. Lastly, although it can take up to an hour stuck in a small MRI machine, most patients prefered the whole-body option, especially f they saw it as a way the number of trips to hospital for scans was also valued by patients.

It's important to note that these findings only refer to colorectal and lung cancer and may not be valid for tumours developing in other parts of the body.

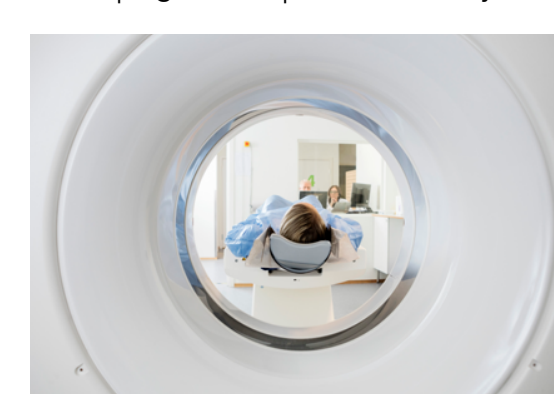

Patients with claustrophobia may struggle to
Also, waiting times and costs may not be the same in other UK hospitals or in hospitals in other countries.

radiologists as ultimately WB-MRI will make cancer staging quicker, cheaper

BARRIERS TO IMPLEMENTATION Despite the highly encouraging results in terms of savings in cost and time, there are some issues with this approach. For example, patients with claustrophobia may struggle to complete a long scan,

\section{REAL-WORLD RESULTS} (nest importan aspects of these trials was the fact that participants were treated exactly the same as every other patient in the NHS. All the imaging was done and interpreted by radiologistsworking and

\section{Results show that the whole-body scan is} quicker, cheaper, and preferred by patients. like a closed tube. However, newer MRI MRI average skill in the national workforce were, which helps claustrophobic patients. Staff. "We are very confident that if with patients who may have some major
reservations about undergoing WB-MR is to offer them the standard scans instead.

From a practical point of view, converting to WB-MRl throughout the country poses other challenges. Not only are most scanners in England already running As Prof Taylor explains "The NHS s. be investing in MRI scanners, and traing open doughnut-shaped scanner, but more scanners are much roomier than they once rather than a highly specialised research at full capacity, but also hospitals lack

\section{A. Behind the Research}

Professor Stuart Taylor

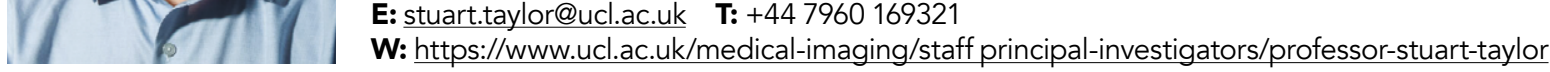

\section{Research Objectives}

Professor Stuart Taylor investigates the benefits of using whole-body MRI to determin

\section{Detail}

Bio

Stuart Taylor is an academic clinical radiologist specialising Professor of Medical Imaging at UCl Iniging. He is expertise aligns around clinical translation of imaging technology, encompassing the translation research pipeline from firstin-man studies through the large-scole prospective multicentre trials.

Funding

National Institute for Health Research (NIHR)

- University College London Hospitals Biomedical Research

Centre

NIHR Birmingham Biomedical Research Centre at the University Hospitals Birmingham NHS Foundation Trust and the University of Birmingham.

\section{UNDED BY}

\section{NIRR $\mid \begin{aligned} & \text { National Institute } \\ & \text { for Health Research }\end{aligned}$}

This project was funded by the National Institute of Health Research health technology assessment NIHR HTA programme (project number 10/68/01)

The views expressed are those of the author(s) and not necessarily those of the NIHR or the Department of Health and Social Care.

\section{Collaborators}

-All study authors, particularly Sue Mallett and Laura Quinn (University of Birmingham), Steve Morris, Steve Halligan, Neal Navani, John Bridgewater and Caroline Clarke (University College London), Anne Miles (Birkbeck University of London)

- The Streamline investigators

- Unver Reseach UKa Uacl Cancer Trials Centre, University College London

\section{References}

Taylor S, Mallett S, Ball S, Beare S, Bhatnagar G, Bhowmik
A, Boavida P, Bridgewater J, Clarke C, Duggan M, Ellis S, Glynne-Jones R, Goh V, Groves A, Hameeduddin A, Janes S, Johnston E, Ko' D, Lock S, M Tes A, Montis S, Morton A, Navani S, Ouinn L, Rafiee H. Reczko K, Rockall A, Russell P. Sidhu H Strickland N, Tarver K, Teague J, Halligan S (2019) Diagnostic accuracy of whole-body MRI versus standard imaging pathways for metastatic disease in newly diagnosed non-small-cell lung cincer: the prospective Str $213-2600$ (19)30090-6.

Taylor S, Mallett S, Beare S, Bhatnagar G, Blunt D, Boavida P, R G Koh D, Miles A, Morris S, Morton A, Navani N, O'Donohue $J_{\text {, }}$ Oliver A, Padhani A, Pardoe H, Patel U, Punwani S, Quinn L, Rafiee H, Reczko K, Rockall A, Shahabuddin K, Sidhu H, Teague $J$, Thaha M, Train M, van Ree K, Wijeyekoon S, Halligan S (2019) Diagnostic accuracy of whole-body MRI versus standard imaging pathways for mectastalic cisease in newly diagnosed Gastroenterol Hepatol. pii: S2468-1253(19)30056-1.

\section{Link to Streamline C}

rology \& Hepatology (colorectal cancer): www.thelancet.com/journals/langas/article/PIIS24681253(19)30056-1/fulltext

The Lancet Respiratory Medicine (non-small cell lung The Lancet Respiratory Medicine (non-small cell lung
cancer): www.thelancet.com/journals/lanres/article/PIIIS22132600(19)30090-6/fulltext Twitter (Centre for Medical Imaging): @CMI_UCL Twitter (Prof Stuart Taylor): @ @protstuartaylor

\section{Personal Response}

\section{What are your next steps to see the results of you} up more widely in the NHS?

II We have shown that in a real-world NHS setting, staging cheaper than the current multi-scan approach. The next steps are for hospitals to start a WB-MRI service for selected patients so as to build up their experience of performing the the scans using workshops and online training resourts many of which are already developed. We must make sure patients are aware of the study results so they can discuss the potential use of WB-MRI with their cancer doctors. I 